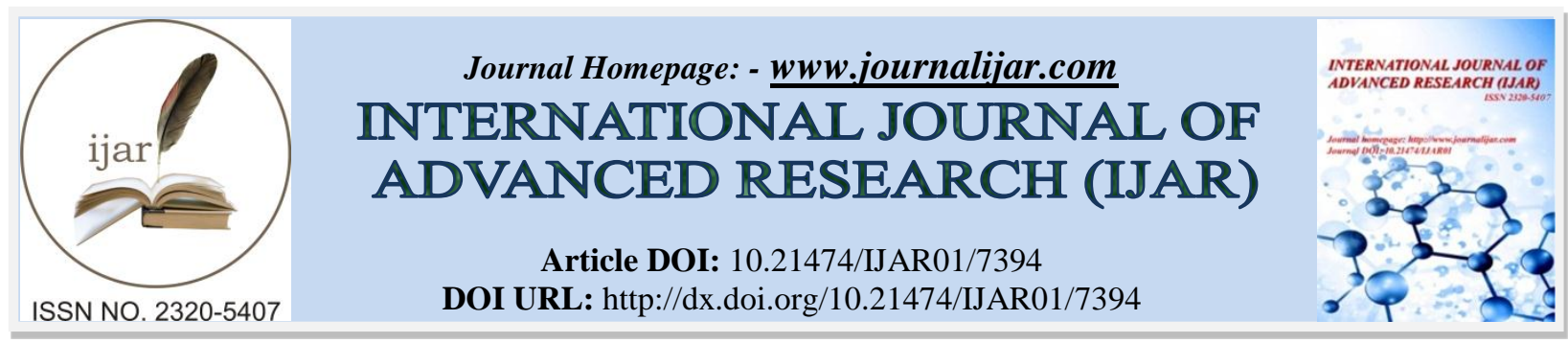

RESEARCH ARTICLE

\title{
OUTCOME ANALYSIS FOLLOWING ILIAC ENDARTERECTOMY IN PATIENTS WITH UNILATERAL ILIAC OCCLUSION.
}

\author{
Prof. N. Sritharan, MS., MCh. ${ }^{1}$, Dr. I. Devarajan, MS, MCh. ${ }^{2}$, Prof.S.Jeyakumar M.S.MCh, Dr. M. Sridhar ${ }^{3}$ \\ and Dr. Jayanth V Kumar, MS, MCh ${ }^{4}$. \\ 1. Professor, Institute of Vascular Surgery, MMC, RGGGH, Chennai-03. \\ 2. Assistant Professor, Institute of Vascular Surgery, MMC, RGGGH, Chennai-03. \\ 3. Senior Resident, Institute of Vascular Surgery, MMC, RGGGH, Chennai-03. \\ 4. Assistant Professor, Institute of Vascular Surgery, MMC, RGGGH, Chennai-03.
}

\section{Manuscript Info}

Manuscript History

Received: 11 May 2018

Final Accepted: 13 June 2018

Published: July 2018

Keywords:-

Iliac endarterectomy, critical limb ischemia.

\section{Abstract}

Objective: Aim of this study is to evaluate the outcomes following unilateral iliac revascularization by iliac endarterectomy in patients with TASC C and TASC D Aorto-iliac lesion, with respect to patency and limb salvage.

Method Of Study: Prospective study.

Results: A total of 26 patients underwent unilateral iliac intervention during the period from August 2016 to January 2017. Mean age at presentation was 68 years(range 45-78). Primary graft patency rate was $92 \%$ at end of 1 year. Limb salvaged rate was $100 \%$. No early graft failure was seen. Late graft failure was seen in one patient.

Conclusion: Unilateral iliac revascularization is a viable option in patients with TASC C and D Aorto- iliac lesions, not amenable to endovascular therapy and severe comorbidities.

Copy Right, IJAR, 2018,. All rights reserved.

\section{Introduction:-}

Aorto-iliac disease generally affects patient of advanced ages with severe co-morbidities. And patients with advanced age were found to have diffuse disease, involving long segments and multilevel occlusion not amenable for endovascular therapy. Aorto- femoral bypass has been the standard operation, against which other results are compared. But Aorto-Femoral bypass has been associated with morbidity and peri-operative mortality, especially in patients with severe co-morbidities.

Iliac endarterectomy followed by ileo-femoral bypass through retroperitoneal approach can be performed with regional anesthesia. It avoids the need for aortic clamping and there by avoids the effects of aortic clamping and declamping.

Extra anatomic bypasses are usually reserved for patients with poor life expectancy. Extra anatomic bypasses have poor patency and limb salvage is less in patients with critical limb ischemia. 


\section{Materials And Methods:-}

A total of 26 patients underwent unilateral iliac intervention during the period from August 2016 to January 2018, at Institute of Vascular Surgery, Madras Medical College, Chennai. They were followed up for a period of one year. All patients were clinically evaluated, Routine work up, Cardiac evaluation, Pulmonary function Test were done. CT Angiogram was done and patients with TASC C and D lesions were included in the study. Patients wound status was stratified based on Rutherford's Classification. All patients underwent Pre-operative Anesthetic evaluation and graded using American Society Anesthesiologist (ASA)Classification System.

Endpoints: Primary Patency and Limb Salvage rate were the primary endpoints. Post-operative Morbidity and Mortality were secondary endpoints. Primary patency defined as patency without repeat intervention not only on the bypass and its anastomoses but also on the donor iliac artery.

Patient Selection Criteria: Patients with TASC C and D Aorto-iliac lesions, not amenable for endovascular therapy, and patients with Severe comorbid conditions, ASA III and ASA IV were included in the study. Patients with TASC A and B Aorto-iliac lesions, and bilateral critical limb ischemia were excluded from the study.

Postoperative assessment: Bypass patency was assessed by clinical pulse evaluation and Ankle Brachial pressure(ABI)measurement. $\mathrm{ABI}$ improvement more than 0.15 of the preoperative $\mathrm{ABI}$, is considered as successful bypass. Groin incisions were checked to detect complications including lymphocele, lymphorrea, and superficial or deep infection.

Follow-up assessment: Follow-up assessment was done after $1^{\text {st }}$ month and after every Outpatient visit. Follow-up assessed using clinical pulse examination and Ankle brachial index measurement. Early graft failure was defined as graft thrombosis occurring within 30 days. Graft surveillance was done in those patients with ABI drop more than 0.15 of the previous value, or patients symptoms of pain and/or absence of previously palpable pulse.

\section{Results:-}

Between August 2016 and January 2018, 26 patients were intervened, for unilateral Iliac Lesions. Following is the observations made. Mean age at presentation was 68 years (range 45-78), comprising of 25 males and 1 female patient.Male sex was most commonly affected involving 25 of 26 patients.Baseline characteristics and risk factors observed are enumerated in the Table 1.

Table 1:-Baseline Characteristics:

\begin{tabular}{|l|l|}
\hline Age in years & $68($ Range 45-78) \\
\hline Male sex & $25(96 \%)$ \\
\hline Female sex & $1(4 \%)$ \\
\hline Risk factors & \\
Tobacco & $24(92 \%)$ \\
Alcohol consumption & $22(84 \%)$ \\
Diabetes mellitus & $13(50 \%)$ \\
Hypertension & $15(57 \%)$ \\
Cardiac dysfunction & $10(38 \%)$ \\
Respiratory dysfunction & $15(57 \%)$ \\
Renal failure & $2(7 \%)$ \\
\hline Pre-operative symptoms & \\
Non-healing ulcer & $6(24 \%)$ \\
Gangrene & $13(50 \%)$ \\
Rest pain & $7(26 \%)$ \\
\hline Iliac lesion with TASC class & \\
TASC C & $15(57 \%)$ \\
TASC D & $11(43 \%)$ \\
With SFA lesion & $9(34 \%)$ \\
\hline Rutherford's class & \\
Class 4 & $7(26 \%)$ \\
Class 5 & $17(57 \%)$ \\
\hline
\end{tabular}




\begin{tabular}{|l|l|}
\hline Class 6 & $2(7 \%)$ \\
\hline ASA III & $9(34 \%)$ \\
ASA IV & $16(61 \%)$ \\
\hline
\end{tabular}

\section{Surgical Technique:-}

All patients underwent Iliac Endarterectomy via Retro-peritoneal approach. Common iliac artery was used as inflow in all the cases. Ileo-femoral bypass was done in $12(46 \%)$ patients. Landing zone was either common femoral artery or profundal femoris artery. Concomitant sequential femoropopliteal or femorotibial bypasses were done in 9(34\%) patients. Aorto-bifemoral conversion was required in $5(20 \%)$ patients. Of the 5 patients who required conversion, there was a plaque disruption to opposite side in 4 patients, and one patient had an aneurysmal degeneration.

Graft patency and Limb salvage:Primary graft patency rate was $92 \%$ at end of 1 year. Limb salvaged rate was $100 \%$. No early graft failure was seen. Late graft failure was seen in one patient. One patient had anastamotic pseudoaneurysm and blow out. He was managed with graft explantation and wound debridement. He was planned for extra-anatomic bypass, but patient declined surgery, as he was an above knee amputee on the opposite side and decided against any further intervention. One patient had late graft failure, three months after the procedure, and was managed with systemic thrombolysis.Other outcomes are detailed in Table 2.

Table 2:-Procedure outcomes and complications

\begin{tabular}{|l|l|}
\hline Procedure done & $12(46 \%)$ \\
Ileo-femoral bypass & $9(34 \%)$ \\
Ile-femoral with sequential bypass & $5(19 \%)$ \\
Aorto-bifemoral conversion & $4(15 \%)$ \\
Plaque disruption to opposite side & $1(3.8 \%)$ \\
Associated aneurysm & \\
\hline Postoperative outcome & $20(76 \%)$ \\
Palpable pulse & $6(23.7 \%)$ \\
Ankle brachial index improvement & \\
\hline Wound infection & 2 \\
Major wound infection & 6 \\
Minor wound infection/ lymphorrea & 1 \\
Paresthesia & 1 \\
\hline Graft thrombosis & 1 \\
\hline Blow out & 11 \\
\hline Toe debridement & 4 \\
Forefoot amputation & $92 \%$ \\
\hline Primary patency & $100 \%$ \\
\hline Limb salvage & \\
\hline
\end{tabular}

Four patients developed plaque disruption to the opposite side, necessitating a Aorto-bifemoral conversion. In one patient there was an associated small infra-renal aortic aneurysm, and needed endoaneurysmorarrphy and aortobifemoral bypass. Immediate post operative outcome as suggested by palpable pulse was seen in $76 \%$ of patients and $23.7 \%$ showed improvement in ankle brachial index. Major wound infection was seen in two patients, one required sartorious flap for groin wound, and other case developed hematoma in the thigh wound which required reexploration and evacuation of hematoma. Both cases had functioning bypass at the end of one year. Minor wound infection developed in $24 \%$ of patients and were managed conservatively with simple wound care.None of the patients required post operative ventilation or developed cardiac events.

\section{Discussion:-}

Patients with unilateral Iliac occlusion, presenting with critical limb ischemia, often require Aorto-femoral bypass. Even though Aorto-femoral bypass can be done by a retroperitoneal approach, the physiological effects of aortic clamping and de-clamping, still adds to the morbidity and mortality. And the presence of severe co-morbidities adds to the complexity, regarding the mode of intervention. All though Endovascular intervention has been advocated in patients with severe co-morbidities, it has been seen that a subset of patients, have diffuse disease and often leads to failed endovascular therapy. 
Iliac endarterectomy through retroperitoneal approach can be done without any of the physiological effects of aortic clamping and declamping. Iliac endarterectomy also removes the disease process at the aorto-iliac bifurcation and provides more of a physiological correction at aorto-iliac bifurcation.The operating time is reduced. Postoperative respiratory and cardiac complications are reduced.

However the risk of plaque disruption to the opposite limb should be borne in mind. Dissection and handling of the artery should be gentle.

\section{Conclusion:-}

Iliac endarterectomy and using the common Iliac artery as an inflow vessel in TASC C and D Aorto-iliac disease is a very useful procedure, especially in patients with severe co-morbidities and in lesions not amenable to endovascular therapy. The results following iliac endarterectomy with ileo- femoral bypass are as good as aortofemoral bypass.

\section{Conflict of interest:-None.}

\section{References:-}

1. Adam van der Vliet, et al. Unilateral vascular reconstruction for iliac obstructive disease. J Vasc SURG 1994;19:610-4.

2. Ricco et al.Long-term results of a multicenter randomized study on direct versus crossover bypass for unilateral iliac artery occlusive disease. J VascSurg 2008;47:45-54.

3. Cham et al. EXTRAPERITONEAL UNILATERAL ILIAC ARTERY BYPASS FOR CHRONIC LOWER LIMB ISCHAEMIA. Aust. N.Z. J. Surg. 1988,58, 859-863

4. Kretschmer et al. Extra-anatomic Femoro-femoral Crossover Bypass (FF) vs. Unilateral OrthotopicIlio-femoral Bypass (IF): An Attempt to Compare Results based on Data Matching. Eur J VascSurg 5, 75-82 (1991)

5. Nazzal et al. A Comparative Evaluation of Femorofemoral Crossover Bypass andIliofemoral Bypass for Unilateral Iliac Artery Occlusive Disease. Angiology. The journal of vascular diseases April 1998.

6. Harrington et al. Iliofemoral case for an versus femorofemoral bypass: The individualized approach. JVASC SURG 1992;16:841-54.

7. Kalman et al. Unilateral iliac disease: The role of iliofemoral bypass. (J VASC SURG 1987;6:139-43.

8. Sidawy et al. Retroperitoneal Inflow procedures for IliacOcclusiveVascular Disease. Arch Surg. Vol.120. July 1985. 